\title{
NET SURFACE RADIATION RETRIEVAL USING EARTH OBSERVATION SATELLITE DATA AND MACHINE LEARNING ALGORITHM
}

\author{
D V Mahalakshmi ${ }^{\mathrm{a}}$, Arati Paul ${ }^{\mathrm{a}^{*}}$, Dibyendu Dutta ${ }^{\mathrm{a}}, \mathrm{M} \mathrm{M} \mathrm{Ali,}^{\mathrm{b}}$ Chandra Sekhar Jha ${ }^{\mathrm{b}}$ and Vinay Kumar Dadhwal ${ }^{\mathrm{b}}$ \\ ${ }^{a}$ Regional Remote Sensing Centre (NRSC), New Town, Kolkata, West Bengal \\ ${ }^{\mathrm{b}}$ National Remote Sensing Centre, Balanagar, Hyderabad
}

\section{Commission VIII, WG VIII/3}

KEY WORDS: ANN, MODIS, Terra, Eddy flux tower, NSR, Bonnie camp.

\begin{abstract}
:
We present a method to estimate net surface radiation (NSR) from Terra MODIS data using Artificial Neural Network (ANN) technique. For this purpose, we trained the ANN model using MODIS atmospheric profile product of air temperature, dew point temperature, solar zenith angle and land surface temperature from Terra as independent parameters and the net surface radiation from eddy flux tower measurements at Bonnie camp location of Sundarban region as the dependent variable. The NSR is estimated with a root mean square accuracy of $64 \mathrm{w} / \mathrm{m}^{2}$ and the square of the correlation coefficient $\left(\mathrm{R}^{2}\right)$ is 0.75 respectively. This technique is extended to estimate NSR over the entire Sundarban area and has a potential for climate and agricultural water management studies.
\end{abstract}

\section{INTRODUCTION}

The radiation (energy) budget of the earth-atmosphere system is currently one of the important research areas in the field of global climate change. Major part of the solar radiation on the earth is reaches as shortwave radiation in the wavelength range of 0.3-4 $\mu \mathrm{m}$ (Badescu, 2008) and as net longwave radiation in the wavelength range of $4-100 \mu \mathrm{m}$. The methodologies to estimate net surface radiation (NSR) can be broadly classified into three categories: (1) ground-only measurements; (2) a combination of remotely sensed data and ground measurements; and (3) remotely sensed data only (Ferreira et al. 2011, Bisth et al, 2005). Several studies reported that ANN has shown its good ability towards the estimations of solar radiation rather than empirical regression models (Sozen et al, 2004, Fadare, 2009 \& Jiang, 2008). But, there are very limited studies available for NSR estimates (Ferreira et al. 2011) by using this technique. Qin et al (2011) used ANN approach to estimate global solar radiation using Moderate Resolution Imaging Spectroradiometer (MODIS) temperature product and vegetation index. However, they did not use the variables directly influencing global solar radiation.

Many researchers (e.g., Bisth et al, 2005, Homan et al., 2011, Jiangtao et al, 2014) have attempted to estimate radiation fluxes at the surface through different parameterization schemes using large number of input parameters. A review of the earlier parameterization schemes for the downwelling surface longwave radiation was given by Ellingson (1995), Niemela et al (2001). The net surface radiation fluxes can be determined from satellites after applying the atmospheric effects. Though the current surface radiation budget products (Ex: ISCPP, CERES) have better temporal resolutions, the spatial resolution is coarse due to which these products are not suitable for land applications. On the other hand, ground based radiation data collected at better temporal scales have poor spatial coverage (Di et al, 2010; Chen and Li, 2012b).

\footnotetext{
* Corresponding author: aratipaul@yahoo.com
}

Hence, a demand exists for alternate approaches to precisely estimate NSR with better spatial and temporal resolutions. In this paper we propose a method to estimate this parameter from MODIS products which are available on large spatio-temporal scales by training an ANN model with the in situ measurements. The trained model is used to estimate NSR over the entire Sundarban area where in situ measurements are not available.

\section{STUDY AREA AND DATA USED}

The study area of Sundarban mangrove forest, comprising of different ecosystems is shown with cross lines in figure 1 . It is a largest continuous stretch of mangrove forests of the world covering about $2.84 \%$ of the global mangrove area. The eddycovariance flux tower was located at Bonnie camp location $\left(21^{0}\right.$ 49'47.87", $88^{\circ} 37^{\prime} 22.33^{\prime \prime E}$ ) of Sundarban region is shown with green color dot in figure 1 . The area is characterised by a web of tidal water systems with very high relative humidity between $70-88 \%$. The mean maximum temperature is $34^{\circ} \mathrm{C}$ in June and the mean minimum temperature is $11^{\circ} \mathrm{C}$ in January.

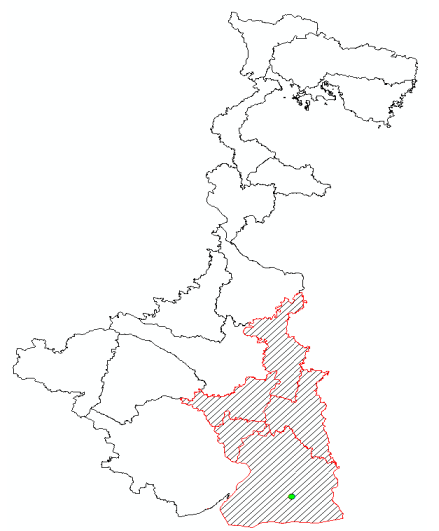

Figure 1: Location of Study area, green color dot indicating the location of the Bonnie camp. 


\subsection{Ground-Based Observations}

The ground based data of NSR are acquired at Bonnie Camp location. Details on the reliability of surface flux observations made by eddy-covariance technique are described by Twine et al (2000). Further details on the sensors available at the tower, the data quality, software used are described by Jha et al. (2013).

\subsection{MODIS atmospheric product}

The characteristics of MODIS sensor may be found in Barnes et al (1998) and Hall et al. (2004). Out of the many products available from MODIS, the atmospheric profiles (MOD07_L2) of Terra MODIS which is provided on a routine basis from MODIS atmospheric science team (Seemann et al., 2003), were used in the present study. The atmospheric profile product contains air temperature, dew-point temperature and atmospheric pressure at 20 fixed pressure levels from 1000hpa to 5hpa with spatial resolution of $5 \mathrm{~km}$. Bisth et al. (2005) used air and dew point temperatures at vertical pressure level of 1000hpa out of 20 pressure levels, as surrogate for the temperatures at screen level height has been considered in the present study. The datasets are obtained from Level 1 and Atmosphere Archive and Distribution System (LAADS) website.

\section{METHODOLOGY}

The data gaps in MOD07 atmospheric parameters were filled by using linear interpolation technique on temporal layers. In addition, we have excluded noisy and suspected data using $3 \times 3$ window median filter technique. Subsequently, the in situ NSR measurements were collocated with the MODIS observations. These collocated observations are used to train the ANN model. The block diagram of the ANN model is shown in Figure 2. In the figure, the input variables are air temperature, dew point temperature, land surface temperature, atmospheric pressure, surface elevation, latitude and solar zenith angle and the output is the NSR. NN is a massive parallel-distributed computer model consisting of simple processing units called artificial neurons that are the basic functioning units (more details are available in Ali et al, 2012 ; Sharma and Ali, 2013).

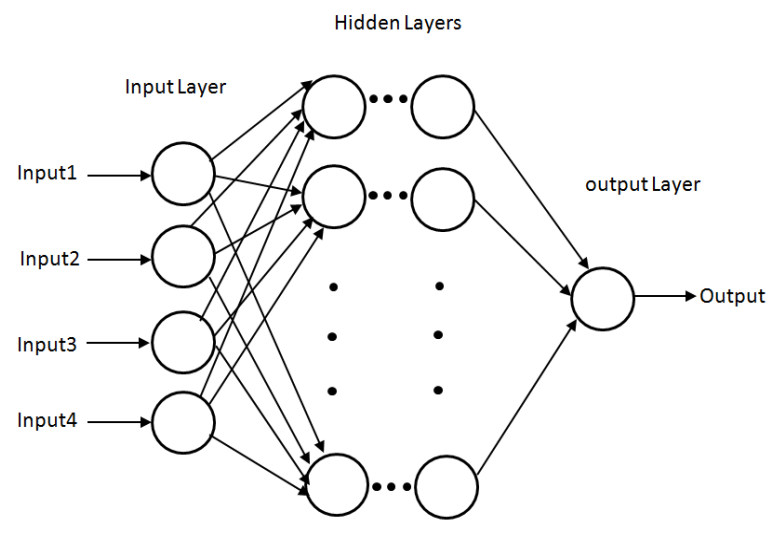

Figure 2: The Block diagram of the ANN

It is proved that NN based estimations of mixed layer depth (Swain et al, 2006) and sonic layer depth (Jain et al, 2012) are better than those from the multiple regression method. ANN analysis requires three sets of data for (1) training, (2) verification and (3) validation. A training dataset is used to train the model and verification set to test the model using independent data during the training process.

The three data sets can be selected either randomly or year-wise. Year-wise data are selected if we are analysing at least three years of data. Since we are analysing only one year data in this study, we randomly selected $70 \%$ of the data for training, $15 \%$ for verification and $15 \%$ for validation (Table 1). However, (Sharma et al, 2013) have shown that the results do not differ significantly by selecting the data either way. We used multilayer perceptrons, which are feed-forward neural networks, with one input layer, seven hidden units, and one output layer. We tried several models, and the present topology is selected based upon the least error. After preliminary examination of input variables, the independent parameters for the ANN model considered are air temperature, dew point temperature, solar zenith angle and land surface temperature at constant pressure level (1000hpa) and the dependent parameter is NSR.

\section{RESULTS AND VALIDATION}

The essence of this study was to investigate the feasibility of using ANN to model the non-linear relationship between NSR and MODIS atmospheric products. Based on the literature survey, it is found that accuracy of ANN model changes with geographical and meteorological variables as input parameters. There are number of meteorological and geographical variables which affect NSR. So, identification of suitable variables for accurate and efficient estimation is important. For the selection of relevant input variables the researcher has to use different combinations of inputs. Therefore, the selection of most important independent variables for ANN is required which is undertaken in the present study. With this main objective, NSR has been estimated with the seven input parameters from MODIS Atmospheric product as per the methodology described in the earlier section. The ground station data from the eddy flux tower were used as target data for the model. This data has been segregated in order to match with MODIS over pass. Effect of number of input parameters were tested on target layer based on statistical feature selection method as shown in figure 3. Since surface elevation and latitude have no impact on the target they are not reflected in the figure.

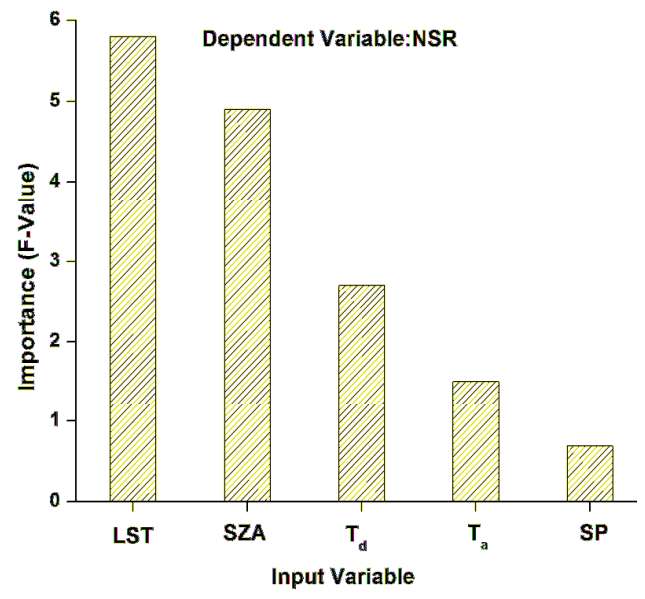

Figure 3: Input variables selection through statistical feature selection method 
Out of the seven input parameters, land surface temperature (LST) is the most important input parameter followed by solar zenith angle (sza), dew point temperature $\left(\mathrm{T}_{\mathrm{d}}\right)$, air temperature and air temperature $\left(\mathrm{T}_{\mathrm{a}}\right)$ and surface pressure $(\mathrm{SP})$. Considering the importance of the parameters, the identified inputs for the network are air temperature, dew point temperature, land surface temperature and sza from the MODIS atmospheric product.

Figure 4 is a scatter between tower measurements with ANN derived NSR, extracted at the location of flux tower. The RMSE and $\mathrm{R}^{2}$ between ANN estimations and the measurements were $64 \mathrm{~W} / \mathrm{m}^{2} \& 0.75$ respectively. However, the best accuracy can be achieved by using large volume of data distributed over the study area. This accuracy is similar to that from the other studies (Ferreira et al. 2011, Bisth et al, 2005 etc). According to Irmak et al. (2003), if NSR could be predicted in an accurate manner from a minimum number of climatological data, this would be a great improvement and contribution for engineers, agronomists, climatologists, and others. In this sense, the ANN introduced here has the ability to estimate NSR using a freely and widely available MODIS data as input. It is obvious that comparisons between $5 \mathrm{~km}$ scale modelled fluxes from MODIS and point measurements from the tower observations contain large uncertainties, especially over large heterogeneity region, with is a limitation for any satellite estimations based on in situ measurements.

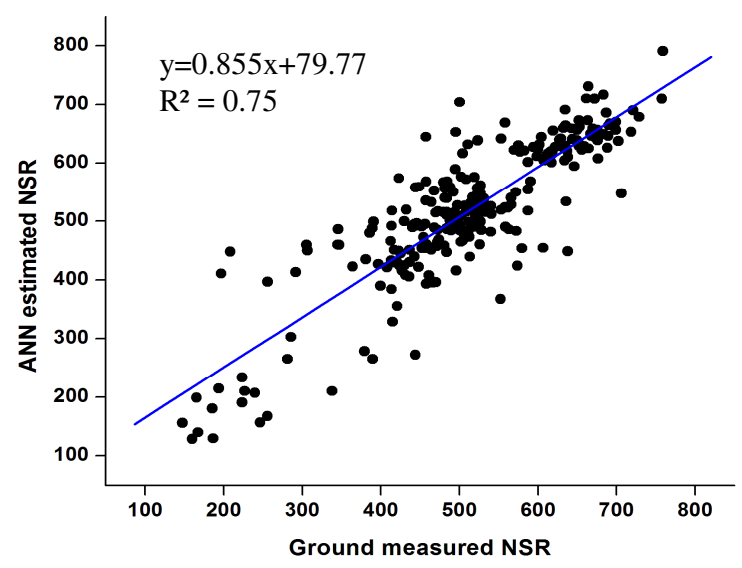

Figure 4: scatter between tower measurements with ANN derived NSR.

This ANN model is used to estimate NSR over the entire Sundarban region, where in situ measurements are not available, using MODIS data. Figure 5 shows typical map of net surface radiation. Daily NSR estimates during the study period show a large spatial variability.

\section{SUMMARY AND CONCLUSION}

Using a combination of tower-based observations, artificial neural networks, and remotely-sensed data, we estimated NSR map over West Bengal region of India. The spatiotemporal patterns are generally reasonable and site-level validation demonstrated the model is able to capture NSR variation. Since the measurements of radiation fluxes have the limitation of spatial and temporal resolution, this approach provides a new way to quantify daily NSR for various ecosystems at a regional scale with a good accuracy.

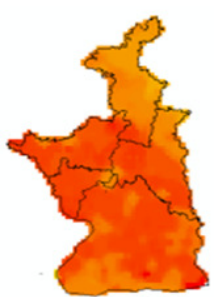

(a)

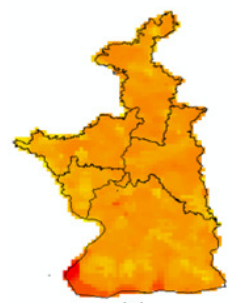

(c)

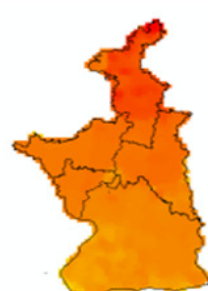

(b)

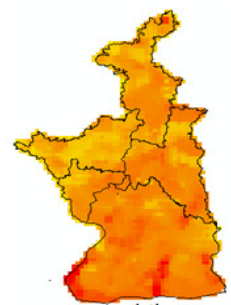

(d)

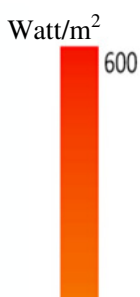

500

400
Figure 5: Instantaneous net radiation map corresponding to julian day (a) 10, (b) 28, (c) 38 and (51) of 2013.

\section{ACKNOWLEDGEMENTS}

This study was funded by the National Carbon Project (NCP). We thank to team of MODIS atmospheric product for providing data.

\section{REFERENCES}

Bisht, G., Venturini V, Islam S and Le Jiang, 2005. "Estimation of the net radiation using MODIS (Moderate Resolution Imaging Spectroradiometer) data for clear sky days" Remote Sens. Environ.,97, 52-67.

Badescu, V. 2008, Modeling Solar Radiation at Earth's Surface, 567 p. Berlin: Springer.

Chen, J.L., Li, G.S., 2012b. Parameterization and mapping of solar radiation in data sparse regions. Asia-Pacific J. Atmos.Sci. 48 (4), 423-431.

Di, Long, Gao, Y., Singh, V.P., 2010. Estimation of daily average net radiation from MODIS data and DEM over Baiyang Watershed in North China for clear sky days.J.Hydrol. 388 (3), 217-233.

Ellingson, R G (1995). Surface longwave fluxes from satellite observations: A critical review. Remote sensing of Environment, 51, 89-97.

Fadare D A (2009). Modeling of solar energy potential in Nirgeria using an artificial neural network model. Applied Energy 86;1410-1422.

Ferreira A G, Soria-Olivas E, Lopez AJS, Lopez-Baiza E, 2011. Estimating net radiation at surface using artificial neural networks: a new approach, Theor Appl Climatol 106, 263-279. 
Gomez, J., Martin, J D, Soria, E., Vila, J.L., \& del Valle, S. (2006). Neural networks for analysing the relevance of imput variables in the prediction of tropospheric ozone concentration. Atmospheric environment, 40, 6173-6180.

Homan, J. W., C. H. Luce, J P Mcnamara, and N. F. Glenn. 2011. "Improvements of Distributed Snowmelt Energy Balance Modeling with MODIS based NDSI-Derived Fractional Snow Covered Area Data." Hydrological Process 25: 650-660.

Irmak S, Asce M, Irmak A, Jones JW, Howell TA, Jacobs JM, Allen RG, Hoogenboom G (2003) Predicting daily net radiation using minimum climatological data. J Irrig Drain Eng 129(4):256-269.

Jha CS, Reddy S R, Chand K T, Raha A K, Dadhwal, V K (2013), Eddy covariance based methane flux in Sundarbans mangroves, India, J.Earth Syst Sci, 123, No.51089-1096.

Jiangtao, H., Gensuo, JIA., Tianbao, Z., Wang, H., \& Tang, B., (2014) Satellite Based estimation of daily average net radiation under clear sky conditions. Adv. Atmos. Sci, Vol31, 705-720.

Jiang, Y. (2008). Prediction of monthly mean daily diffuse solar radiation using artificial neural networks and comparison with other empirical models. Energy Policy, 36, 3833-3837.

King M D., Kaufman, Y.J., Menzel, W.P., \& Tanre, D (1992). Remote sensing of cloud, aerosol, and water vapour properties from the Moderate Resolution Imaging Spectroradiometer (MODIS). IEEE Transactions on Geoscience and Remote Sensing, 30, 2-27.

M M Ali, P S V Jagadeesh, I-I Lin, and Je-Yuan Hsu, "A Neural Network Approach to Estimate Tropical Cyclone Heat Potential in the Indian Ocean", IEEE Geoscience and Remote Sensing Letters, vol. 9, pp 1114 - 1117, 2012.

Niemela, S., Raisanen, P., Savijarvi, H. (2001). Comparison of surface radiative flux parameterizations: Part I. Longwave radiation. Atmospheric Research, 58, 1-18.

Sozen A, Arcaklioglu E, Ozalp M E, Galip Kanit EG(2004). Use of artificial neural networks for mapping of solar potential in Turkey, Applied Energy, 77, 273-286.

Seemann, S. W., Li, J., Menzel, W.P., \& Gunley, L.E. (2003). Operational retrieval of atmospheric temperature, moisture, and ozone from MODIS infrared radiances. Journal of Applied Meteorology, 42, 1072-1091.

Sharma N, MM Ali, John A. Knaff and Purna Chand, "A softcomputing cyclone intensity prediction scheme for the Western North Pacific Ocean", Atmospheric Science Letters, vol. 14, pp 187-192, DOI:10.1002/asl2.438, 2013.

Sharma, N and M. M. Ali , "An approach to predict cyclogenesis using radio occultation observations", Int. J. Engg. and Innovative Technology, vol. 3, pp 364-367, 2013.

Swain D, M.M Ali, and R.A.Weller, Estimation of mixed layer depth from surface parameters, J. Mar. Res. Vol. 64, pp 745758,2006
S. Jain, MM Ali and PN Sen "Estimation of Sonic Layer Depth from Surface Parameters", Geophys. Res. Lett. vol. 34, Doi:10.1029/2007GL030577, 2012.

Twine, T. E., W. P. Kustas, J. M. Norman, D. R. Cook, P. R. Houser, T. P. Meyers, J. H. Prueger, P. J. Starks, and M. L. Wesely, Correcting eddy- covariance flux underestimates over a grassland, Agric. For. Meteorol.,103, 279- 300, 2000. 